\section{BRAZIULIAN JOURNAL \\ OF MEDICAL AND BIOLOGICAL RESEARCH}

www.bjournal.com.br
ISSN 1414-431X

Volume 45 (12) 1102-1340 December 2012

\section{BIOMIDICAL SCIENCES}

AND

CLINICAL INVESTIGATION

Braz J Med Biol Res, December 2012, Volume 45(12) 1315-1319

doi: 10.1590/S0100-879X2012007500150

Oculo-facio-cardio-dental syndrome in three succeeding generations: genotypic data and phenotypic features

B. Lozić, J. Ljubković, D. Gabrić Pandurić, I. Saltvig, K. Kutsche, V. Krželj and T. Zemunik

The Brazilian Journal of Medical and Biological Research is partially financed by

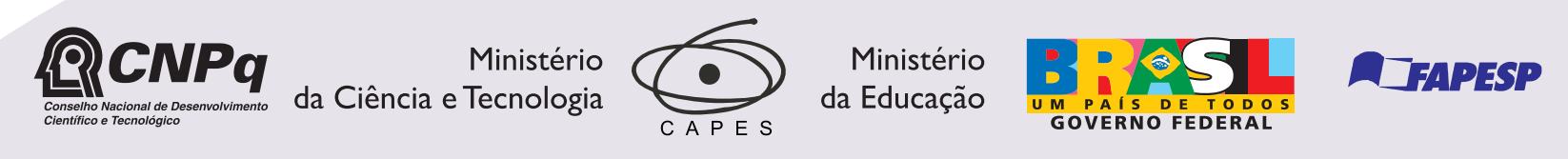

Institutional Sponsors

Sciefo
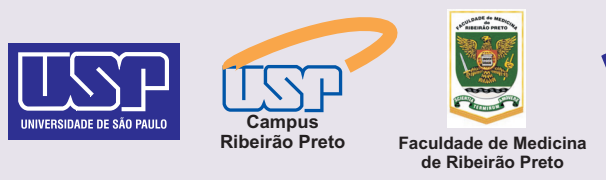

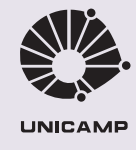

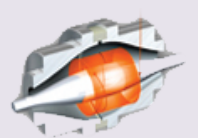

Ф SHIMADZU

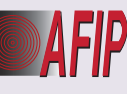

Associaçăa de Incentivo
à Pesquisa

plore High - Performance MS Orbitrap Technology analitica Thermo 


\title{
Oculo-facio-cardio-dental syndrome in three succeeding generations: genotypic data and phenotypic features
}

\author{
B. Lozić ${ }^{1}$, J. Ljubković ${ }^{2}$, D. Gabrić Pandurić ${ }^{3}$, I. Saltvig ${ }^{4}$, K. Kutsche ${ }^{5}$, \\ V. Krželj ${ }^{1}$ and T. Zemunik 6 \\ ${ }^{1}$ Department of Pediatrics, University Hospital Split, Split, Croatia \\ 2Department of Pathology, Forensic Medicine and Cytology, University Hospital Split, Split, Croatia \\ ${ }^{3}$ Department of Oral Surgery, School of Dental Medicine, University of Zagreb, Zagreb, Croatia \\ ${ }^{4}$ Jessenius Faculty of Medicine of Commenius, University in Bratislava, Martin, Slovakia \\ 5 Institute of Human Genetics, University Medical Center Hamburg-Eppendorf, Hamburg, Germany \\ ${ }^{6}$ Department of Medical Biology, School of Medicine, University of Split, Split, Croatia
}

\begin{abstract}
Oculo-facio-cardio-dental (OFCD) syndrome is a rare X-linked disorder mainly manifesting in females. Patients show ocular, facial, cardiac, and dental abnormalities. OFCD syndrome is caused by heterozygous mutations in the BCOR gene, located in Xp11.4, encoding the BCL6 co-repressor. We report a Croatian family with four female members (grandmother, mother and monozygotic female twins) diagnosed with OFCD syndrome who carry the novel BCOR mutation c.4438C >T (p.R1480*). They present high intrafamilial phenotypic variability with special regard to cardiac defect and cataract that showed more severe disease expression in successive generations. Clinical and radiographic examination of the mother of the twins revealed a talon cusp involving the permanent maxillary right central incisor. This is the first known report of a talon cusp in OFCD syndrome with a novel mutation in the BCOR gene.
\end{abstract}

Key words: OFCD syndrome; BCOR gene; Talon cusp; Intrafamilial phenotypic variability

\section{Introduction}

Oculo-facio-cardio-dental (OFCD) syndrome is characterized by ocular defects (congenital cataract, microphthalmia, secondary glaucoma), facial anomalies (long and narrow face, high nasal bridge, septate nasal cartilage, cleft palate), congenital cardiac defects [atrial septal defect (ASD), ventricular septal defect (VSD), floppy mitral valve], and dental irregularities (canine radiculomegaly, hypodontia, delayed permanent dentition) (1). It is an X-linked disorder manifesting mainly in females. Several incidences with mother-to-daughter transmission have been described, and females with OFCD syndrome show a completely skewed pattern of X-chromosome inactivation $(2,3)$.

Genetic studies have led to the identification of heterozygous mutations in the BCOR gene, encoding the BCL6 co-repressor, in patients affected by OFCD (4). The mutation spectrum comprises nonsense, frameshift and splicing mutations, supporting the hypothesis that OFCD syndrome is caused by heterozygous BCOR null alleles $(1,4,5)$. Usually dentists are the first clinicians who notice characteristic manifestations of this disorder. The most consistent dental finding is radiculomegaly; the roots of the maxillary incisors and canines can continue to grow until they reach the cortical plate of the orbit or the lower border of the mandible, usually with widely open apices $(6,7)$. Oligodontia, delayed eruption of the dentition, retained primary teeth, malocclusion, root dilacerations, macrodontia, fusion of teeth, hyperdontia, variable root length, and enamel defects are other dental findings that have been reported in OFCD syndrome $(6,7)$.

Talon cusp or dens evaginatus is a very rare dental anomaly of unclear etiology and significance. W.H. Mitchell was the first who described this morphological anomaly in 1892 (8). It was named a talon cusp by Mellor and Ripa (9) due to its resemblance to an eagle's talon. The most

Correspondence: T. Zemunik, Department of Medical Biology, School of Medicine, University of Split, Šoltanska 2, 21000 Split, Croatia. Fax: +385-21-557-895. E-mail: tzemunik@mefst.hr

Received May 19, 2012. Accepted September 10, 2012. Available online September 21, 2012. Published December $17,2012$. 
commonly affected teeth are maxillary incisors. It can occur as an isolated finding or be associated with other dental anomalies or some syndromes such as Mohr syndrome (oro-facial-digital II), Sturge-Weber syndrome (encephalotrigeminal angiomatosis), Rubinstein-Taybi syndrome, incontinentia pigmenti achromians, Ellis-van-Creveld syndrome, hypomelanosis of Ito, cleft lip and palate, and Alagille syndrome (10).

We report a family with 4 affected female patients in three generations, demonstrating vertical transmission of OFCD syndrome. The novel BCOR nonsense mutation c.4438C > T (p.R1480*) was identified in the monozygotic twins, their mother and maternal grandmother in the heterozygous state. We performed careful phenotypic analysis in all patients with special emphasis on discordant phenotypes in monozygotic female twins and describe a unique case of a maxillary talon cusp associated with OFCD syndrome.

\section{Patients and Methods}

\section{Ethical approval}

Clinical data and samples were obtained from the participating family members with informed consent, including consent to use photographs in this report. Genotyping protocols were approved by the University Medical Center Hamburg-Eppendorf Ethics Committee.

\section{Case report}

Monozygotic female twins (twin 1 and twin 2) were conceived after in vitro fertilization. Two embryos were transferred; one of them survived and divided to produce monozygotic twins. The twins were born at $32 / 33$ weeks of gestation by cesarean section.

Birth weight of twin 1 was $1540 \mathrm{~g}$ (10-25th centile) and length was 42 $\mathrm{cm}$ (10-25th centile). During clinical examination, she was noted to have long philtrum, mildly broad nasal tip, asymmetric size of eyes, downward eyebrows, and congenital cataract of both eyes. Cataract surgery completely removed a cloudy lens of the eye because of inability of light penetration at the age of 4 months (Figure 1). She had additional anomalies: umbilical hernia, camptodactyly of 2nd and 3rd toes of the right foot, and echocardiography revealed ASD. Patients with ASD are usually asymptomatic in infancy and childhood. However, in ventricular septal defect. our patient, the defect was getting larger with appearance of moderate pulmonary hypertension followed by dyspnea and growth failure. Therefore, surgical closure of ASD at the age of 8 months was successfully performed to prevent development of Eisenmenger syndrome (Table 1).

Twin 2 was more severely affected than her twin sister at newborn age. Her birth weight was $1660 \mathrm{~g}$ (10-25th percentile) and length was $41 \mathrm{~cm}$ (10-25th percentile). She had dolichocephaly, long face, bilateral microphthalmia, bilateral cataract with completely cloudy lens, ptosis and downward eyebrows, long philtrum, mildly broad nasal tip, cleft dental ridge in midline, high palate, partial syndactyly of 2nd and 3rd toes on the left side, and broad hallux on both sides (Figure 1). Internal examinations showed congenital heart defect with ASD and VSD that were asymptomatic. Cardiologic assessment showed that cardiac defects tended to close spontaneously over time as the child grew. At the age of 7 months the cataracts were surgically removed and

Table 1. Clinical features of family members with OFCD syndrome.

\begin{tabular}{|c|c|c|c|c|}
\hline Clinical findings & $\begin{array}{c}\text { Twin } 1 \\
\text { (1 year old) }\end{array}$ & $\begin{array}{c}\text { Twin } 2 \\
\text { (1 year old) }\end{array}$ & $\begin{array}{c}\text { Mother } \\
\text { (32 years old) }\end{array}$ & $\begin{array}{l}\text { Grandmother } \\
\text { (53 years old) }\end{array}$ \\
\hline \multicolumn{5}{|l|}{ Ocular } \\
\hline Congenital cataract & $+/ \mathrm{CC}$ & $+/ \mathrm{CC}$ & $+/ I C$ & $+/ I C$ \\
\hline Microphthalmia & - & + & - & - \\
\hline Ptosis & - & + & + & - \\
\hline Coloboma of the iris & - & - & + & - \\
\hline Nystagmus & - & - & + & - \\
\hline \multicolumn{5}{|l|}{ Facial } \\
\hline Broad nasal tip & + & + & - & + \\
\hline Long philtrum & + & + & + & + \\
\hline Long face & - & + & + & + \\
\hline Downward eyebrows & + & + & - & - \\
\hline Cleft dental ridge & - & + & - & - \\
\hline High palate & - & + & + & + \\
\hline \multicolumn{5}{|l|}{ Cardiac } \\
\hline ASD/VSD & + & + & - & - \\
\hline \multicolumn{5}{|l|}{ Skeletal } \\
\hline Camptodactyly of toes 2-3 & + & - & + & - \\
\hline Syndactyly of toes $2-3$ & - & + & + & + \\
\hline Broad halluces & - & + & + & - \\
\hline \multicolumn{5}{|l|}{ Dental } \\
\hline Delayed dentition & NA & NA & + & + \\
\hline Oligodontia & NA & NA & + & + \\
\hline Radiculomegaly & NA & NA & + & + \\
\hline Talon cusp & NA & NA & + & - \\
\hline \multicolumn{5}{|l|}{ Other } \\
\hline Developmental delay & + & + & - & - \\
\hline Umbilical hernia & + & - & - & - \\
\hline
\end{tabular}

OFCD = oculo-facial-cardio-dental syndrome; $(+)$ = present; $(-)=$ absent; $C \mathrm{C}$ = complete cataract; IC = incomplete cataract; NA = not applicable; ASD/VSD = atrial septal defect/ 
intraocular lenses were implanted.

In both cases, visual impairment due to cataracts in early infancy was related to global developmental delay and they were referred to vision habilitation/rehabilitation services. Clinical evaluation of both twins at the age of 12 months revealed mild to moderate developmental delay and failure to thrive. They were unable to sit independently. Oral examination of the twin infants was unexceptional; both girls were edentulous (Table 1).

Examination of the 32-year-old mother of the monozygotic twins revealed normal height, weight and head circumference, with a high number of congenital anomalies including facial dysmorphism: long face, long philtrum, left ptosis, iris coloboma, and horizontal nystagmus (Figure 1). Thoracic kyphoscoliosis, syndactyly of 2 nd and 3rd toes with camptodactyly of the second toe on the left side and broad hallux on both sides were also noted. She reported a normal psychomotor development and her intelligence

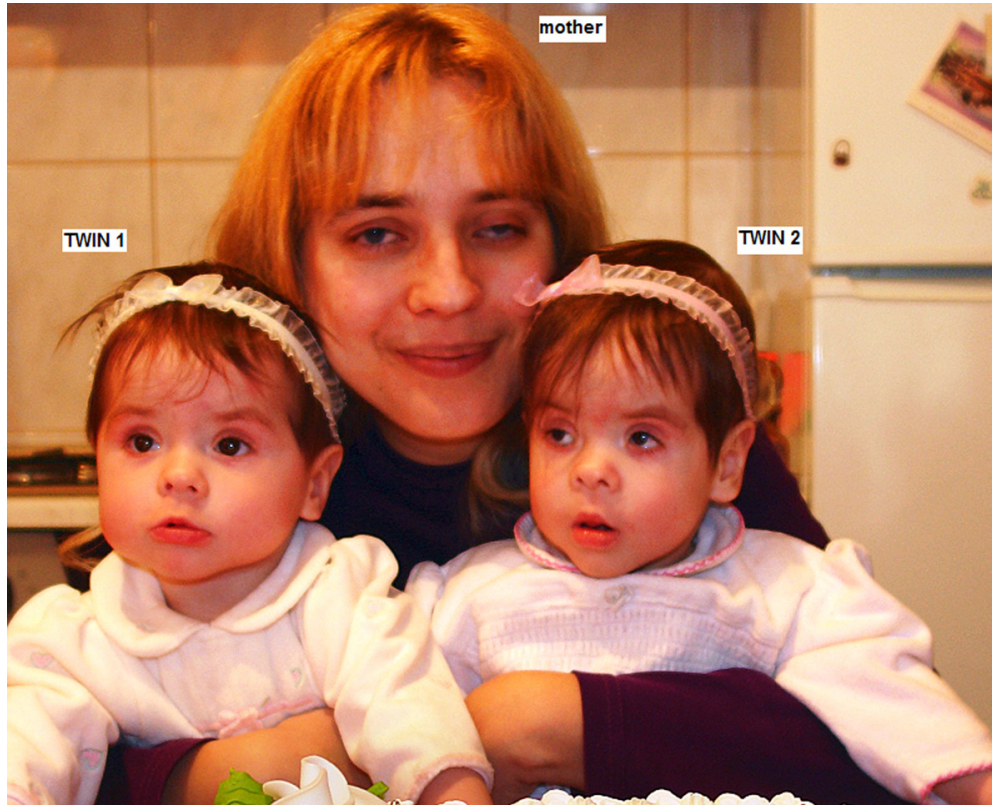

Figure 1. Dysmorphic facial features typical of oculo-facio-cardio-dental (OFCD) syndrome in the 32-year-old mother and her 1-year-old monozygotic twins.
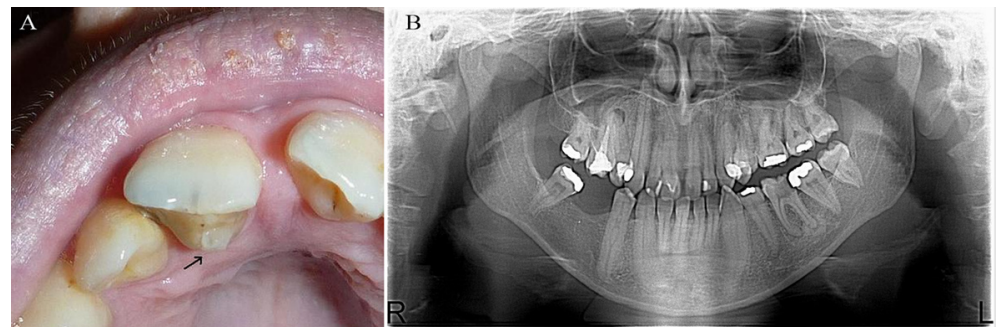

Figure 2. $A$, Intraoral photograph of the twins' mother showing talon cusp of the maxillary right central incisor. $B$, Orthopantomogram of the twins' mother. was above average. In early childhood, she was diagnosed with a heart murmur but with no heart defect. She was born with bilateral incomplete (incipient) cataract. After cataract surgery, performed at the age of 2 years, she developed subsequent glaucoma at the age of 12 years. She has been wearing glasses since her third year of life due to a high refractive error. Low vision is more pronounced in the left eye. She did not get pregnant for 5 years before the affected twins were born after in vitro fertilization.

Oral examination of the twins' mother showed several missing teeth and class II malocclusion with extremely deep overbite, highly arched palate, thickened maxillary frenulum with a 3-mm diastema between the upper central incisors, dens evaginatus or talon cusp of the maxillary right central incisor (Figure 2A), also recognized later on the orthopantomogram (OPG; Figure 2B). In addition, slight yellowish discoloration of the upper frontal teeth without enamel defects was found. OPG revealed radiculomegaly and root dilaceration of all four canines and lower right first premolar (Figure 2B). On the OPG, hypodontia of three second premolars and third molars was found on the right side. The lower right first premolar also showed an unusual appearance and morphology of the endodontic space. Review of her dental history indicated delayed eruption in both dentitions (Table 1).

Examination of the 53-year-old maternal grandmother of the monozygotic twins showed facial dysmorphism (long face, long philtrum, mildly broad nasal tip) and syndactyly of 2nd and 3rd toes on both sides. She was born with bilateral incomplete cataract that was operated in the second year of life. She developed subsequent glaucoma. Because of glaucoma she gradually lost vision in the right eye after her twenties and in the left eye after her thirties. Today she is blind due to congenital cataracts and secondary glaucoma, because during the operation in childhood no intraocular lenses were implanted. She had no cardiac disorders and she is not mentally disabled.

OPG of the twins' maternal grandmother revealed radiculomegaly and root dilacerations of the three canines. Review of her dental history indicated radiculomegaly of the extracted upper right canine due to complicated surgical removal of the tooth with the elongated root. Clinical examination showed high arched palate, numerous missing teeth and class II malocclusion with mild overbite on the remaining frontal teeth. Her dental history revealed delayed dental eruption and hypodontia of all four first premolars and of 
the lower right lateral incisor (Table 1).

\section{Genotypic data}

In order to confirm monozygotic twins, postnatal DNA analysis of autosomal short tandem repeat (STR) loci was performed using the MiniFiler PCR Amplification Kit (Applied Biosystems, Germany) and showed that their STR profiles were identical.

The coding region of the BCOR gene (exons 2-15; GenBank accession No. NM_001123385) and flanking intronic sequences were PCR-amplified from genomic DNA of the twins' mother. Primer sequences are available on request. Amplicons were directly sequenced using the $A B I$ BigDye Terminator Sequencing Kit (Applied Biosystems) and an automated capillary sequencer (ABI 3500; Applied Biosystems). Sequence electropherograms were analyzed using the Sequence Pilot software (JSI Medical Systems, Germany). Subsequently, BCOR exon 11 was amplified from genomic DNA of the 2 twins and their grandmother and directly sequenced.

We identified the heterozygous nonsense mutation c. $4438 \mathrm{C}>\mathrm{T}$ (p.R1480*) in exon 11 of BCOR in the mother of the twins. Sequencing of $B C O R$ exon 11 in the DNA samples of the monozygotic twins and their grandmother revealed the same transition in the heterozygous state.

\section{Discussion}

We report here 4 females belonging to the same family with phenotypes typical of OFCD syndrome. Sequencing of the $B C O R$ gene revealed a novel nonsense mutation (p.R1480*) in all of them and confirmed the clinical diagnosis. OFCD syndrome is inherited as an X-linked condition predominating in females, with high intrafamilial variability of the phenotypic outcome $(2,11)$. This was also noticed in our study where all patients showed different phenotypic manifestations of the disease. Also, this is the first report of non-mosaic monozygotic twins with a BCOR gene mutation. A previous study reported identical twins with classical OFCD syndrome phenotype, but deletion of at least BCOR exons 4-15 was present in somatic mosaicism in both (6). The discordant congenital heart defect in the monozygotic twins described here evolved to a symptomatic type in early infancy in twin 1 and to a mild type in twin 2. Cardiac involvement in the present family ranged from asymptomatic to structural defects requiring surgery in infancy. The severity of cardiac defects showed increased expression in succeeding generations of the same family. At the same time, the severity of cataracts also showed pronounced expression in succeeding generations. It is anticipated that even mental development could follow this tendency. The high clinical variability in OFCD syndrome has been suggested to be due to $X$-chromosome inactivation skewing in females with a $B C O R$ mutation (3). Indeed, the influence of X-chromosome inactivation on the phenotypic outcome has been discussed before for two other X-linked dominant male-lethal disorders, such as the microphthalmia with linear skin defects syndrome and the oral-facial-digital type I syndrome (12). Thus, dosage compensation of the mammalian X-chromosome influences the phenotype of X-linked diseases manifesting primarily in females (12).

The most important clinical criteria leading to the diagnosis of OFCD syndrome are dental abnormalities, in particular extreme radiculomegaly of the canines and sometimes other teeth that we could demonstrate in our 2 adult patients. Radiculomegaly was found in almost all reported patients $(6,7)$. Even in adult patients, the affected teeth showed vast extension of the root and open apices. Moreover, radiculomegaly was present in permanent incisors and premolars as we reported here. In both of our adult patients, we noticed dental anomalies such as oligodontia, delayed dental eruption, malocclusion, canine radiculomegaly, and root dilacerations that have also been described in the literature $(6,7)$. An interesting dental finding was noticed in the twins' mother who showed dens evaginatus or talon cusp of the maxillary right central incisor, which is a rare dental anomaly in the normal population and has been reported in association with several other syndromes (8-10). Maxillary incisors are most frequently affected by talon cusp. We confirmed the presence of a talon cusp in the mother of the twins by clinical and X-ray diagnosis. To the best of our knowledge, this is the first report of a talon cusp in a patient with molecularly confirmed OFCD syndrome. Talon cusp has not been previously reported in OFCD syndrome even though dental findings are of particular interest in this disorder.

In summary, we undertook careful phenotypic analysis of 4 affected individuals in three successive generations of one family, all carrying a novel nonsense mutation in the $B C O R$ gene. The most interesting finding was pronounced expression of cardiac defects and cataract in succeeding generations. Similar observations of increased clinical severity in successive generations have been reported by others (3). The second important observation was a talon cusp in a patient with genetically confirmed OFCD syndrome. This specific dental finding can be added to the dental abnormalities seen in females with this disorder. We suggest that talon cusp should be considered as a potential clinical predictor of OFCD syndrome, before X-ray diagnosis can be performed to uncover radiculomegaly as well as other dental anomalies.

\section{Acknowledgments} study.

We are grateful to the family for participating in this 


\section{References}

1. Oberoi S, Winder AE, Johnston J, Vargervik K, Slavotinek AM. Case reports of oculofaciocardiodental syndrome with unusual dental findings. Am J Med Genet A 2005; 136: 275277.

2. Wilkie AO, Taylor D, Scambler PJ, Baraitser M. Congenital cataract, microphthalmia and septal heart defect in two generations: a new syndrome? Clin Dysmorphol 1993; 2: 114-119.

3. Hedera P, Gorski JL. Oculo-facio-cardio-dental syndrome: skewed $\mathrm{X}$ chromosome inactivation in mother and daughter suggest X-linked dominant inheritance. Am J Med Genet $A$ 2003; 123A: 261-266.

4. Horn D, Chyrek M, Kleier S, Luttgen S, Bolz H, Hinkel GK, et al. Novel mutations in BCOR in three patients with oculofacio-cardio-dental syndrome, but none in Lenz microphthalmia syndrome. Eur J Hum Genet 2005; 13: 563-569.

5. Ng D, Thakker N, Corcoran CM, Donnai D, Perveen R, Schneider A, et al. Oculofaciocardiodental and Lenz microphthalmia syndromes result from distinct classes of mutations in BCOR. Nat Genet 2004; 36: 411-416.

6. Hilton E, Johnston J, Whalen S, Okamoto N, Hatsukawa $Y$, Nishio J, et al. BCOR analysis in patients with OFCD and
Lenz microphthalmia syndromes, mental retardation with ocular anomalies, and cardiac laterality defects. Eur J Hum Genet 2009; 17: 1325-1335.

7. Schulze BR, Horn D, Kobelt A, Tariverdian G, Stellzig A. Rare dental abnormalities seen in oculo-facio-cardio-dental (OFCD) syndrome: three new cases and review of nine patients. Am J Med Genet 1999; 82: 429-435.

8. Mitchell WH. Letter to the editor. Dental Cosmos 1892; 34: 1036.

9. Mellor JK, Ripa LW. Talon cusp: a clinically significant anomaly. Oral Surg Oral Med Oral Pathol 1970; 29: 225-228.

10. Dinesh RB, Hegde S. A talon cusp on fused teeth associated with hypodontia: report of a unique case. Eur J Dent 2010; 4: 75-80.

11. McGovern E, Al-Mudaffer M, McMahon C, Brosnahan D, Fleming P, Reardon W. Oculo-facio-cardio-dental syndrome in a mother and daughter. Int J Oral Maxillofac Surg 2006; 35: 1060-1062.

12. Morleo M, Franco B. Dosage compensation of the mammalian $X$ chromosome influences the phenotypic variability of X-linked dominant male-lethal disorders. J Med Genet 2008; 45: 401-408. 